\title{
Evaluation of immunological response of gingival tissue injected by meloxicom
}

\author{
Lekaa M. Ibraheem , B.D.S.,M.Sc., Hashim D.Musa, B.D.S. ,M.Sc. , PhD. \\ Prof. Periodontology. College of Dentistry .Baghdad University. Baghdad-Iraq. \\ Lecturer .Periodontology .Hawler Medical University. College of Dentistry. Iraq
}

\begin{abstract}
:
Background: Periodontitis, defined as an inflammatory disease of the supporting tissue of the teeth caused by specific microorganisms resulting in progressive destruction of the periodontal ligament and alveolar bone with pocket formation, recession or both.

Although bacteria are considered to be the primary etiologic agents of periodontal disease the pathogenesis of periodontitis involves host-bacterial interaction followed by release of inflammatory mediators such as eicosanoids and cytokines. Arachidonic acid metabolites, mainly prostaglandins of the E series $\left(P G E_{2}\right)$, seem to be critical mediators in the progression of periodontal disease.

Meloxicam inhibits prostaglandin synthetase (cylooxygenase 1 and 2) and leads to a decrease of the synthesis of prostaglandins, therefore, inflammation is reduced.

Aim of the study: To evaluation of immunological parameters after sulcular injection of meloxicam on periodontium, throughout measuring the level of cytokine such as interlukine-1 beta (IL-1 beta) and tumor necrosis factor-alpha (TNF-alpha) in blood of rabbit.
\end{abstract}

Materials and Methods: Forty five male rabbits of same species were divided into three groups as following: Group1: included 20 rabbits that injected with meloxicam with a dose equivalent to human therapeutic dose using insulin syringe,

Group2: included 15 rabbits were injected with normal saline as the same volume of drug and

Group3: include 10 rabbits were left without interference to be used as a control group.

After sulcular injecting of meloxicam and normal saline in lower right central incisor tooth, $5 \mathrm{ml}$ of blood had been collected for later analyzing of immunological analysis which include interlukine-1 beta (IL-1 beta) and tumor necrosis factor-alpha (TNF-alpha)

Results: The meloxicam injected group had produced initially higher level of TNF- $\alpha, I L-1 \beta$ than normal saline after $3^{\text {rd }}$ day of injection then there was highly significance reduction at day 14 in meloxicam injected group in compare to other groups.

Conclusion: In this study, it was shown that sulcular injection of COX-2 inhibitor meloxicam reduce gingival inflammation by reducing proinflammatory mediators with no gastric damage and no remaining effect can be expected after its withdrawal.

Key word: Meloxicom, periodontitis, IL-1 $\beta$ and TNF- $\alpha$

\section{Introduction:}

NSAIDs exert their anti-inflammatory effect through inhibition of prostaglandinG/H synthase, or cyclooxygenase, which is the enzyme catalyzing the transformation of arachidonic acid to prostaglandins and thromboxanes ${ }^{(1)}$ (Carin et al., 2006).

Non-Steroidal Anti-Inflammatory Drugs (NSAIDS) have been used to treat pain of acute or chronic inflammation. They are effective in inhibition of prostaglandin synthesis. They limit the progression of periodontitis through their ability to reduce inflammation and bone resorption. A pathway involved in periodontal disease pathogenesis involves the synthesis and release of prostaglandins and other arachidonic acid metabolites within periodontal tissues. Both bacterial and host factors initiate tissue damage. ${ }^{(2)}$ (Howell \& Williams, 1993)

Meloxicam is a nonsteroidal anti inflammatory drug (NSAID) belonging to the class of oxicams. In addition to its analgesic \& antipyretic effect it is widely used in the treatment of rheumatoid arthritis , ankylosing sponulytis \& osteoarthritis.(3) (Laurent \& Annette, 2000).

Interleukin-1 is a potent proinflammatory cytokine produced in $\alpha$ - and $\beta$-forms. It is an early mediator of the inflammatory and overall immune responses and can as such influence the host response in periodontal lesions. Interleukin-1 $\beta$ (IL-1 $\beta$ ) is the major inflammatory cytokine occurring in gingival tissues affected by periodontitis(4) (Tokoro et al. 1996). It is produced primarily by monocytes, macrophages and polymorphonuclear phagocytes, as well as by epithelial cells, keratinocytes in the skin, gingival and dermal 
fibroblasts, B cells and osteocytes. By mediating the production of potent inflammatory molecules, such as prostaglandins and cytokines, IL-1 $\beta$ has a central role in tissue destruction(5) (Delaleu \& Bickel 2004). It also plays a crucial part in regulation of immune and inflammatory responses such as $\mathrm{T}$ and $\mathrm{B}$-cell activation, and in collagenase release, and is one of the most potent proinflammatory cytokines stimulating bone resorption(6) (Kornman et al. 1997). Mononuclear cells and macrophages producing IL-1 $\beta$ have been associated with the host's susceptibility to early-onset periodontitis(7) (Salvi et al. 1998). IL-1 $\beta$ increases degranulation of neutrophils by potentiating their response to other stimuli and by increasing the release of other proinflammatory substances, such as tumour necrosis factor- $\alpha$ (TNF- $\alpha$ ) and interleukin-8(8,9) (Brandolini et al. 1997, Sfakianakis et al. 2001). It may also modulate periodontal ligament cell function allowing these cells to participate directly in the disease process by assuming responsiveness to lipopolysaccharides at the expense of their normal structural properties and functions(10) (Agarwal et al. 1998). Interleukin $-1 \beta$ and TNF- $\alpha$ have been shown to be of particular importance in connective tissue resorption(11) (Meikle et al. 1989), where TNF$\alpha$ induces the secretion of collagenase by fibroblasts(4) (Tokoro et al. 1996). An increased release of IL-1 $\beta$ and TNF- has been demonstrated in mononuclear cells cultured from the peripheral blood of patients with chronic periodontal disease(12) (McFarlane et al. 1990). Tumor necrosis factor - $\alpha$ from monocytes and macrophages has synergistic effects with IL-1 cytokines, although it is somewhat less potent than IL-1(13) (Okada \& Murakami 1998)

Host Modulation Therapy is a treatment concept that aims to reduce tissue destruction and stabilize or even regenerate the periodontium by modifying or down regulating destructive aspects of host response and up regulating protective or regenerative responses. The purpose of host modulatory therapy is to restore balance between on the one hand, proinflammatory mediators and destructive enzymes and on the other hand antiinflammatory mediators and enzyme inhibitors. They can be systemically administered or locally delivered and used as adjuncts to scaling and root planning(14). (Oringer, 2002)

Aim of the study is to evaluate the immunological response after sulcular injection of meloxicam on periodontium , throughout measuring the level of cytokine such as interlukine-1 beta (IL-1 $1 \beta$ ), tumor necrosis factor- alpha (TNF- $\alpha)$ in blood.

\section{Material and method:}

The present study was carried out in Duhok Medical University, College of Dentistry, Department of Periodontology, and department of basic science during the period between the middle of July 2011 until the end of May 2012.

Forty five rabbits of both sexes that weighted (1-1.5 kg), 2-3 months old were used in this study. They were allowed to acclimatize at least 7 days prior to the experiment to ensure the same type of food to be taken by these rabbits at a temperature of $25-30{ }^{\circ} \mathrm{C}$. Rabbits kept in pairs in stainless cages, tags with different numbers were fixed on the rabbit's ear to mark them.

The samples were divided into three groups:

Group 1: included 20 rabbits that injected (sulcular injection) with meloxicam with a dose equivalent to human therapeutic dose/kg using insulin syringe.

Group 2: included 15 rabbits were injected (sulcular injection) with normal saline as the same volume of drug .

Group 3: include 10 rabbits were left without interference to be used as a control group.

Sulcular injection technique was used through the labial gingival tissue of lower right central incisor by inserted the needle approximately $5 \mathrm{~mm}$ into gingival tissue at the buttom of gingival sulcus, the specified amount of solution was delivered to the site over a period of approximately ten seconds (Peterson et al.,1983)(15)

Five $\mathrm{ml}$ of blood was collected from the rabbits ear vein for immunological analysis which measured at deferent time interval, after 1, 3, 7, 10 and 14 days of giving sulcular injection.

\section{Immunological assay included:}

Serum IL-1 $\beta$ which analysed by using Assay Max Human Interleuken-1 $\beta$ (IL-1 $\beta$ ) ELISA Kit

TNF- $\alpha$ was measured by using RayBio_ Human TNF-alpha ELISA Kit . Quantification of IL-1 $\beta$,TNF$\alpha$ were determined by use of enzyme -linked immunosorbent assay kits. Multiple cytokine expression concentrations were simultaneously determined according to the manufacture's instruction.

\section{Results}

The mean and SD of TNF- $\alpha$ in the injected group with Meloxicam after 1 day was $184.89 \pm 14.58$ and increased to reach $201.94 \pm 24.25$ after 3 days of injection then gradually reduced to reach $145.09 \pm 9.45$ after 14 days of injection. For the normal saline injected group the mean and SD was $118.60 \pm 12.99$ after 1 day and reduced to $109.50 \pm 1.49$ after 10 days of injection then increased to reach $160.91 \pm 15.92$ after 14 days of injection. While it was $65.13 \pm 15.14$ for the control group as shown in table-1- 
The meloxicam has produced initially higher level of (TNF- $\alpha$ ) than normal saline followed by gradual declined after 3rd day of injection. The final increase in the level of (TNF- $\alpha)$ in normal saline group could be due to measurement error. day period.

In meloxicam group, there was no significant differences between the 1 st day with the $3 \mathrm{rd}$ and 10 th

While in normal saline group there were only significant differences in regard to the 14th day which could be due to measurement error as shown in fig-1

The mean and SD of IL-1 $\beta$ in the injected group with Meloxicam after 1 day was $241.29 \pm 16.80$ and increased to reach $288.52 \pm 16.22$ after 3 days and reduced to reach $213.50 \pm 12.01$ after 14 days of injection. For the normal saline injected group the mean and SD was $228.47 \pm 27.95$ after 1 day and increased to reach $229.91 \pm 28.57$ after 3 days and reduced to $199.81 \pm 23.71$ after 14 days of injection. While it was $186.45 \pm 14.72$ for the control group as shown in table -2-

Initially there was similar level of (IL1- $\beta$ ) in both groups with slight increase in the level of (IL1- $\beta$ ) at the 3rd day in both groups but more in meloxicam group followed by gradual decline in both groups as shown in fig -2-

\section{Discussion}

Periodontal diseases affect tens of millions of people, and tooth loss, as well as potential systemic effects of infection and local inflammation, as a result of periodontitis continues to be a public health problem. Although bacteria appear to cause periodontitis, the progression of the disease is dependent on the host response to pathogens that colonize the tooth surface. While the removal of bacteria reduces tissue destruction, not all individuals respond predictably to elimination of bacteria alone(16)( Brook, 2003). Therefore, in addition to bacterial control, adjunctive host modulation therapy may aid in the prevention of the disease or enhance clinical therapeutic responses in the susceptible host. Recent work has demonstrated that, in addition to bacterial control, modulation of the host's immunoinflammatory response is also capable of controlling periodontitis(17) (Serhan et al., 2003).

Serum or plasma provides information about the inflammatory stimulus and/or response generated in circulation towards the periodontal pathogens that colonize in the subgingival area(18) (Pussinen et al. 2007). Increased circulating levels of cytokines were reported in chronic periodontitis patients compared with the clinically healthy control subjects(!9) (Mooney \& Kinane 1994).

During the initiation of an inflammatory response in the periodontal connective tissue, numerous cytokines, such as prostaglandin E2 (PGE2), interleukin (IL)-1, or tumor necrosis factor (TNF- $\alpha$ ) are released from cells of the junctional epithelia, connective tissue fibroblasts, macrophages, and PMNs. Subsequently, T and $\mathrm{B}$ cells emerge at the infection sites and secrete immunoglobulins as an antigen-specific response(6).(Kornman et al.,1997).

Tumor necrosis factor $-\alpha$ is a less potent stimulator of PGE2 production compared to IL-1 $\beta$, but these two cytokines synergistically enhance PGE2 production(20) (Yücel-Lindberg et al. 1999).

Our results revealed that there is significant reduction in the level of TNF- $\alpha$ among different period after sulcular injection of meloxicam, while in normal saline group there was initial increase in the level of TNF- $\alpha$ followed by declined which didn't reach the level of meloxicam group.

The role of the host response in periodontal bone loss is complex. There is evidence that a deficient host response increases periodontal destruction and at the same time evidence that a too vigorous response leads to PDS.

The first conclusive evidence that host response played an important role was shown when treatment with a prostaglandin inhibitor reduced the amount of bone loss(21) (Williams et al .,1985).Evidence that cytokines played a critical role was shown in non- human primate model. In this report, inhibition of interleukin ( IL)-1 and tumor necrosis factor (TNF) reduced the progression of periodontal bone loss and loss attachment(22) (Delima et al .,2001), which was attributed to the recruitment of inflammatory cells (notably monocytes and lymophocytes ) toward the bone(23)(Graves et al ., 1998).

Meloxicam is an NSAID of the oxicam class, that acts by inhibiting prostaglandin synthesis and inducible COX-2, thereby exerting anti-inflammatory and subsequently reduced proinflammatory mediators which included TNF- $\alpha(24)$ (Papatsas et al.,2004)

Animal models showed that bacteria stimulate periodontal tissue destruction but that this effect is mediated by the host response induced by bacteria. By using inhibitors ,it was shown that cytokines play an important role in this process. The effects of cytokines that promote osteoclast formation and bone resorbtion seem to be counteracted by other cytokines that are anti-inflammatory It is probable that the balance between stimulatory and inhibitory cytokines, together with the regulation of their receptors and signaling cascades, determines the level of periodontal tissue loss .Another complicating factor is the deficient coupling that occurs 
in periodontal bone loss so that the expected replacement of resorbed bone is inadequate leading to net bone loss. The host response induced by bacteria may also play a role in uncoupling .

From human and animal models ,there is strong evidence of a role for IL-1 in mediating bone loss stimulated by periodontal pathogens .In humans, IL-1 $\beta$ expression was elevated in gingival crevicular fluid at sites of recent bone and attachment loss in patient with periodontal disease(25)( Lee et al ., 1995).

Interlukin $-1 \beta$ is a central mediator of inflammation and connective tissue destruction in rheumatoid arthritis (Raymond et al. 2006). IL-1 $\beta$ increases matrix degradation also by inducing the production of PGE2 in synovial cells, as well by its role as a mediator of bone and cartilage destruction(26) (Cutulo 2004).

During the host's innate defense response to bacterial lipopolysaccharide (LPS), monocytes, PMNs, macrophages, and other cells release IL-1,TNF, and PGE2(27)(Ozmeric N,2004).

In healthy periodontium, initially there was similar level of (IL-1 $\beta$ ) in both groups with slight increase in the level of this marker at day 3 in meloxicom group followed by gradual decline in both groups.

After sulcular injection of meloxicam there was decrease in the level of inflammatory biomarker (IL$1 \beta)$ after 3days of injection, while in the same day there was increase in the level of (IL-1 $\beta$ ) after normal saline injection, then the inflammatory biomarker declined in both groups, the decline was similar at the end of 2 weeks in our study, while, In periodontal research, the effects of soluble receptors and receptor antagonists of IL-1 and TNF- $\alpha$ have been studied during experimentally induced periodontitis in a non-human primate model (e.g. Macaca fascicularis)(28,29) (Delima et al. 2001, 2002, Oates et al. 2002). Collectively, the clinical, radiographic and biochemical findings of these experiments showed that IL-1 and TNF- $\alpha$ antagonists blocked (i) the progression of the inflammatory cell infiltrate towards the alveolar crest, (ii) the recruitment of osteoclasts and (iii) periodontal attachment and bone loss.

Based upon the increased expression of IL-1 and TNF in inflamed gingival and high levels in the GCF of periodontitis patients, several studies have suggested that increased production of these cytokines may play an important role in periodontal tissue destruction(30) (Graves \& Cochran 2003).

The result of this study is agree with study done by Buduneli $\mathrm{N}$ et al 2010(31) found that systemic administration of $7.5 \mathrm{mg}$ of meloxicam cause significant reduction of IL- $1 \beta$ level in chronic periodontitis patients

This result was disagree with the study done by Toker, 2006(32) who found that meloxicam did not reveal any influence on level of IL-1 $\beta$ In GCF in chronic periodontitis(Toker, Marakoglu, Poyraz ,2006).

The beneficial effects following NSAID therapy are mainly a result of the inhibition of the metabolic transformation of arachidonic acid into prostanoids, especially prostaglandins of the $\mathrm{E}$ series, via the $\mathrm{COX}$ pathway(33)(Holzhausen.,et al, 2002)

\section{Reference}

[1]. Carin E. Dugowson, MD, MPH,Priya Gnanashanmugam, MD.(2006). Nonsteroidal Anti-Inflammatory Drugs. Phys Med Rehabil Clin N Am;17:347-354

[2]. Howell TH, Williams RC(1993).Nonsteroidal antiinflammatory drugs as inhibitors of periodontal disease progression. Critical Reviews in Oral Biology \& Medicine;4(2):177-96.

[3]. Laurent B \& Annette M.(2000).Effects of meloxicam, Diclofenac, \& Aceclofenac on the Metabolism of Proteoglycans \& Hyaluronan in Osteoarthritic Human Cartilage. British Journal of Pharmacology; 131: 1413- 1421

[4]. Tokoro Y, Yammamoto T, Hara K. IL-1 (1996). beta mRNA as the predominant inflammatory cytokine transcript: correlation with inflammatory cell infiltration into human gingiva. J Oral Pathol Med; 25:225-231

[5]. Delaleu N, Bickel M. (2004). Interleukin-1beta and interleukin-18: regulation and activity in local inflammation. Periodontol 2000; $35: 42-52$

[6]. Kornman KS, Crane A, Wang HY, di Giovine FS, Newman MG, Pirk FW and others. (1997). The interleukin-1 genotype as a severity factor in adult periodontal disease. J Clin Periodontol; 24:72-7

[7]. Salvi GE, Brown CE, Fujihashi K, Kiyono H, Smith FW, Beck JD, Offenbacher S. (1998). Inflammatory mediators of the terminal dentition in adult and early onset periodontitis. J Periodont Res;33:212-225

[8]. Brandolini L, Sergi R, Caselli G, Boraschi D, Locati M, Sozzani S, Bertini R. (1997). Interleukin-1beta primes interleukin-8 stimulated chemotaxis and elastase release in human neutrophils via its type I receptor. Eur Cytokine Netw; 8:173-178

[9]. Sfakianakis A, Barr CE, Kreutzer DL.(2001).Actinobacillus actinomycetemcomitans-induced expression of IL-1alpha and IL-1beta in human gingival epithelial cells: role in IL-8 expression. Eur J Oral Sci; 109:393-401

[10]. Agarwal S, Chandra CS, Piesco NP, Langkamp HH, Bowen L, Baran C. (1998). Regulation of periodontal ligament functions by Interleukin- 1beta. Infect Immun; 66:932-937

[11]. Meikle MC, Atkinson SJ, Ward RV, Murphy G, Reynolds JJ. (1989). Gingival fibroblasts degrade type 1 collagen films when stimulated with tumor necrosis factor and interleukin 1: evidence that breakdown is mediated by metalloproteinases. J Periodontol Res; 24:207-213

[12]. McFarlane CG, Reynolds JJ, Meikle MC. (1990). The release of interleukin- $\beta$, tumor necrosis factor- $\alpha$ and interferon- $\gamma$ by cultured peripheral blood mononuclear cells from patients with periodontitis. J Periodontol Res.; 25:207-214.

[13]. Okada H, Murakami S. (1998). Cytokine expression in periodontal health and disease. Crit Rev Oral Biol Med;9:248-266

[14]. Oringer R.(2002) Modulation of the host response in periodontal therapy. Journal of Periodontology;73(4):460-70

[15]. Oringer R.(2002) Modulation of the host response in periodontal therapy. Journal of Periodontology;73(4):460-70

[16]. Brook, I.( 2003). Microbiology and management of periodontal infections.Gen.Dent; 51:424-428

[17]. Serhan, C. N., A. Jain, S. Marleau, C. Clish, A. Kantarci, B. Behbehani, S. P. Colgan, G. L. Stahl, A. Merched, N. A. Petasis, L. Chan, and T. E. Van Dyke. (2003). Reduced inflammation and tissue damage in transgenic rabbits overexpressing 15-lipoxygenase and endogenous anti-inflammatory lipid mediators. J. Immunol;171:6856-6865 
[18]. Pussinen, P. J., Paju, S., Mantyla, P. \& Sorsa, T. (2007). Serum microbial- and host-derived markers of periodontal diseases: a review. Current Medical Chemistry; 14: 2407-2412

[19]. Mooney, J. \& Kinane, D. F. (1994).Humoral immune responses to Porphyromonas gingivalis and Actinobacillus actinomycetemcomitans in adult periodontitis and rapidly progressive periodontitis. Oral Microbiology and Immunology; 9:321326

[20]. Yucel-Lindberg T, et al. (1999) Signal transduction pathways involved in the synergistic stimulation of prostaglandin production by interleukin-1beta and tumor necrosis factor alpha in human gingival fibroblasts. J Dent Res;78(1):61-8.

[21]. Williams RC,Jeffcoat MK,Kaplan ML, Goldhaber P,Johnson HG,Wechter(1985). Flurbiprofen:A potent inhibitor of alveolar bone resorption in beagles;227:640-642

[22]. Delima, A. J., Oates, T., Assuma, R., Schwarzt, Z., Cochran, D. L., Amar, S. \& Graves, D. T. (2001) Soluble antagonists to interleukin-1 (IL-1) and tumor necrosis factor (TNF) inhibits loss of tissue attachment in experimental periodontitis. Journal of Clinical Periodontology;28:233-240

[23]. Graves, D. T., Delima, A. J., Assuma, R., Amar, S., Oates, T. \& Cochran, D. L. (1998). Interleukin- 1 and tumor necrosis factor antagonists inhibit the progression of inflammatory cell infiltration toward alveolar bone in experimental periodontitis. Journal of Periodontology; 69:1419-1425

[24]. Papatsas I, Georgoulakis IE, Filiousis G, Alexopoulos G \& Kyriakis SC (2004). Proc 18th IPVS Congress, p 175.

[25]. Lee H. J., Kang I. K., Chung C. P. and Choi S. M. (1995). The subgingival microflora and gingival crevicular fluid cytokines in refractory periodontitis. J. Clin. Periodontol,; 22: 885-890

[26]. Cutulo, M. (2004). IL-1Ra: its role in rheumatoid arthritis. Rheumatismo; 56: 41-45

[27]. Ozmeric N. Advances in periodontal disease markers.(2004). Clin Chim Acta ;343:1-16

[28]. Delima, A. J., Karatzas, S., Amar, S. \& Graves, D. T. (2002). Inflammation and tissue loss caused by periodontal pathogens is reduced by interleukin-1 antagonists. Journal of Infectious Diseases; 186: 511-516

[29]. Oates, T. W., Graves, D. T. \& Cochran, D. L. (2002). Clinical, radiographic and biochemical assessment of IL-1/TNF-a antagonist inhibition of bone loss in experimental periodontitis. Journal of Clinical Periodontology; 29: 137-143

[30]. Graves DT. and Cochran D. (2003). The communication of interleukin-1 and tumour necrosis factor to periodontal tissue destruction. J Periodontol; 74: 391-401

[31]. Buduneli, N., Buduneli, E., C, etin, E. O., Kirilmaz, L.\& Ku“tu“kc u“ler, N. (2010). Clinical findings andgingival crevicular fluid prostaglandin E2 and interleukin-1-beta levels following initial periodontal treatment and short-term meloxicam administration. Expert Opinion on Pharmacotherapy;11:1805-1812

[32]. Toker, H., Poyraz, O. \& Eren, K. (2008). Effect of periodontal treatment on IL-1beta, IL-1ra, and IL- 10 levels in gingival crevicular fluid in patients with aggressive periodontitis. Journal of Clinical Periodontology; 35: 507-513.

[33]. Holzhausen M, Rossa Junior C, Marcantonio Junior E, Nassar PO, Spolidorio DM, Spolidorio LC.(2002). Effect of selective cyclooxygenase-2 inhibition on the development of ligature-induced periodontitis in rats. J Periodontol ;73:1030-6

Table -1- Descriptive analysis of (TNF- $\alpha)$ for control group and injection groups

\begin{tabular}{|c|c|c|c|c|c|c|c|c|c|}
\hline & \multirow[t]{2}{*}{$\mathrm{N}$} & \multirow[t]{2}{*}{ Mean } & \multirow[t]{2}{*}{ Std. Deviation } & \multirow[t]{2}{*}{ Std. Error } & \multirow{2}{*}{$\begin{array}{l}95 \% \text { Confidence Interval for } \\
\text { Mean } \\
\text { Lower Bound } \\
\end{array}$} & \multirow{2}{*}{\begin{tabular}{|l|} 
Minimum \\
Upper Bound \\
\end{tabular}} & \multirow{2}{*}{ Maximum } & & \\
\hline & & & & & & & & & \\
\hline \multirow{6}{*}{ Meloxicam } & After 1 day & 4 & 184.8900 & 14.58096 & 7.29048 & 161.6884 & 208.0916 & 169.80 & 203.30 \\
\hline & After 3 days & 4 & 201.9475 & 24.25628 & 12.12814 & 163.3503 & 240.5447 & 179.60 & 231.20 \\
\hline & After 7 days & 4 & 162.0575 & 13.87030 & 6.93515 & 139.9868 & 184.1282 & 145.62 & 179.21 \\
\hline & After 10 days & 4 & 164.8875 & 6.66980 & 3.33490 & 154.2744 & 175.5006 & 158.78 & 173.41 \\
\hline & After 14 days & 4 & 145.0925 & 9.45706 & 4.72853 & 130.0442 & 160.1408 & 133.25 & 156.12 \\
\hline & Total & 20 & 171.7750 & 24.19946 & 5.41116 & 160.4493 & 183.1007 & 133.25 & 231.20 \\
\hline \multirow{6}{*}{ Normal saline } & After 1 day & 3 & 118.6067 & 12.99647 & 7.50351 & 86.3217 & 150.8917 & 109.70 & 133.52 \\
\hline & After 3 days & 3 & 124.0667 & 5.51936 & 3.18660 & 110.3558 & 137.7775 & 119.50 & 130.20 \\
\hline & After 7 days & 3 & 118.4500 & 4.24887 & 2.45309 & 107.8952 & 129.0048 & 113.80 & 122.13 \\
\hline & After 10 days & 3 & 109.5033 & 1.49901 & 86545 & 105.7796 & 113.2271 & 108.40 & 111.21 \\
\hline & After 14 days & 3 & 160.9167 & 15.92014 & 9.19150 & 121.3688 & 200.4645 & 144.35 & 176.10 \\
\hline & Total & 15 & 126.3087 & 20.29244 & 5.23948 & 115.0711 & 137.5462 & 108.40 & ] 176.10 \\
\hline Control & Total & 10 & 65.1310 & 15.14222 & 4.78839 & 54.2989 & 75.9631 & 48.81 & 90.51 \\
\hline
\end{tabular}

Table -2- Descriptive analysis of (IL-1 $\beta$ ) for control group and injection groups

\begin{tabular}{|c|c|c|c|c|c|c|c|}
\hline & & $\mathrm{N}$ & Mean & Std. Deviation & Std. Error & Minimum & Maximum \\
\hline \multirow{6}{*}{ Meloxicam } & After 1 day & 4 & 241.2975 & 16.80692 & 8.40346 & 223.23 & 262.45 \\
\hline & After 3 days & 4 & 288.5250 & 16.22990 & 8.11495 & 265.50 & 301.23 \\
\hline & After 7 days & 4 & 245.2462 & 13.79542 & 6.89771 & 225.68 & 256.05 \\
\hline & After 10 days & 4 & 227.9348 & 12.82162 & 6.41081 & 209.75 & 237.97 \\
\hline & After 14 days & 4 & 213.5085 & 12.01013 & 6.00506 & 196.47 & 222.91 \\
\hline & Total & 20 & 243.3024 & 28.87486 & 6.45661 & 196.47 & 301.23 \\
\hline \multirow{5}{*}{ Normal saline } & After 1 day & 3 & 228.4733 & 27.95536 & 16.14003 & 199.60 & 255.41 \\
\hline & After 3 days & 3 & 229.9167 & 28.57792 & 16.49947 & 199.56 & 256.30 \\
\hline & After 7 days & 3 & 199.0067 & 1.67482 & .96696 & 197.50 & 200.81 \\
\hline & After 10 days & 3 & 206.5100 & 21.51005 & 12.41883 & 188.68 & 230.40 \\
\hline & After 14 days & 3 & 199.8167 & 23.71566 & 13.69224 & 177.31 & 224.58 \\
\hline
\end{tabular}




\begin{tabular}{|c|c|c|c|c|c|c|c|}
\hline & Total & 15 & 212.7447 & 23.99889 & 6.19649 & 177.31 & 256.30 \\
\hline Control & Total & 10 & 186.4550 & 14.72593 & 4.65675 & 166.32 & 212.40 \\
\hline
\end{tabular}

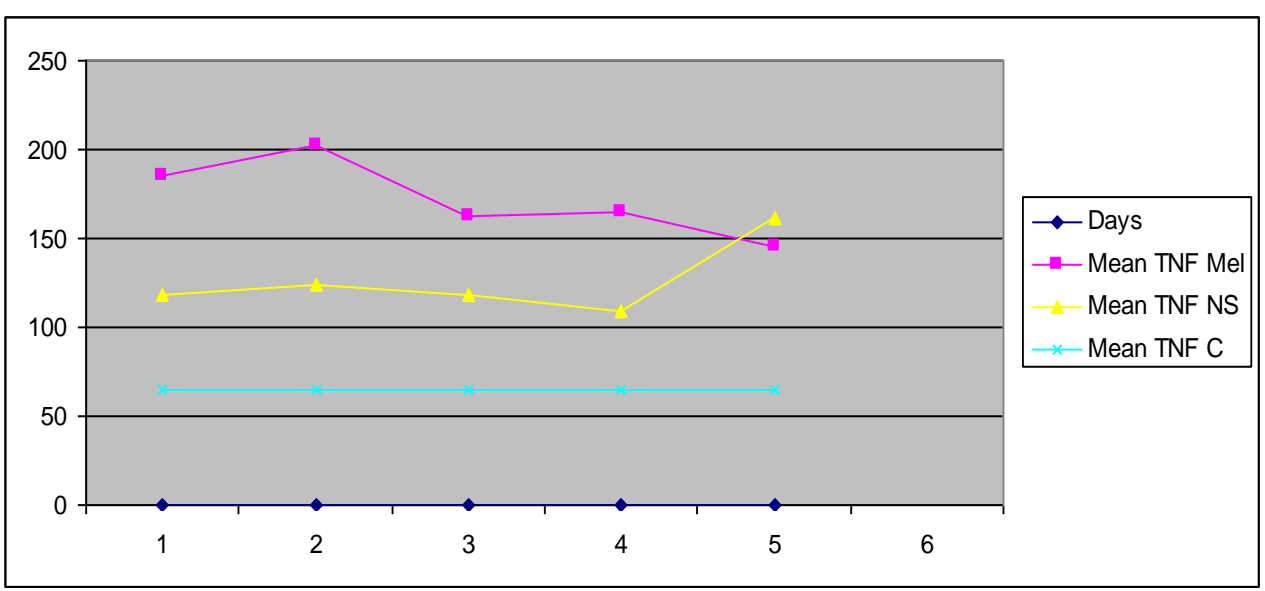

Fig -1- Mean of TNF- $\alpha$ level among groups at different time interval

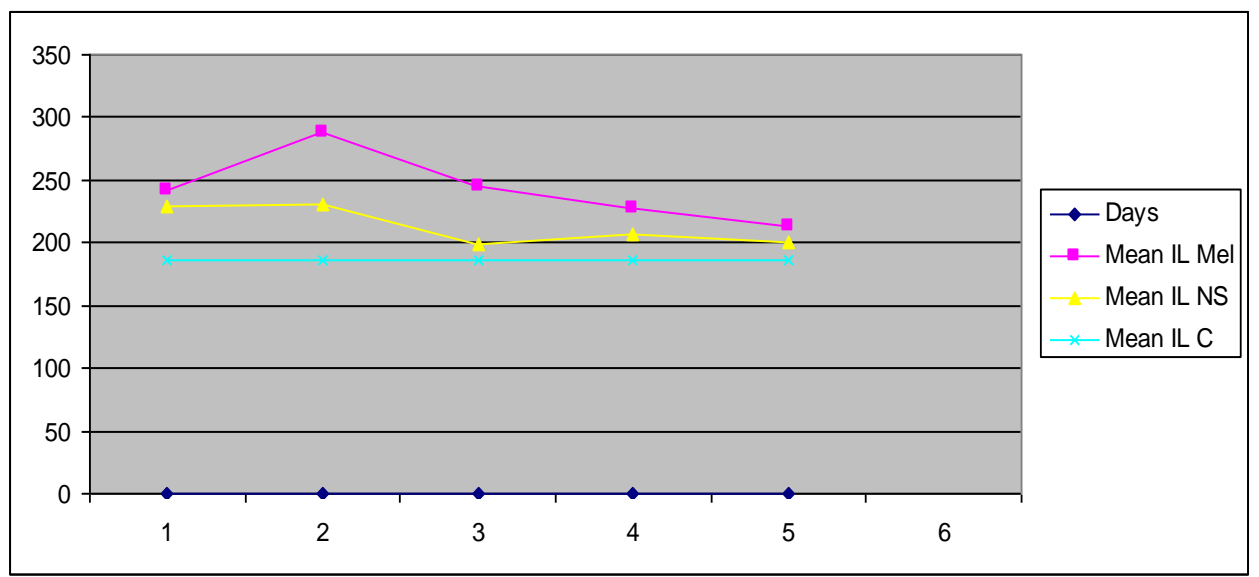

Fig -2- Mean of IL1- $\beta$ among groups at different time interval 